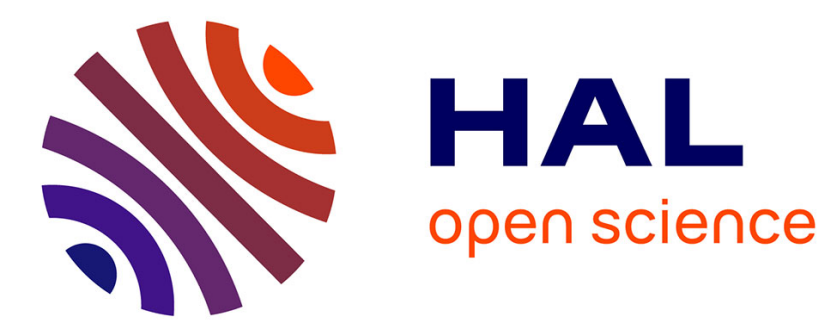

\title{
Mid-position treatment strategy for locally advanced lung cancer: a dosimetric study
}

M Ayadi, T. Baudier, G Bouilhol, P Dupuis, P. Boissard, R. Pinho, A.

Krason, S Rit, L. Claude, D. Sarrut

\section{- To cite this version:}

M Ayadi, T. Baudier, G Bouilhol, P Dupuis, P. Boissard, et al.. Mid-position treatment strategy for locally advanced lung cancer: a dosimetric study. British Journal of Radiology, 2020, 93 (1110), pp.20190692. 10.1259/bjr.20190692 . hal-02948227

\section{HAL Id: hal-02948227 \\ https://hal.science/hal-02948227}

Submitted on 2 Oct 2020

HAL is a multi-disciplinary open access archive for the deposit and dissemination of scientific research documents, whether they are published or not. The documents may come from teaching and research institutions in France or abroad, or from public or private research centers.
L'archive ouverte pluridisciplinaire HAL, est destinée au dépôt et à la diffusion de documents scientifiques de niveau recherche, publiés ou non, émanant des établissements d'enseignement et de recherche français ou étrangers, des laboratoires publics ou privés. 


\title{
Mid-position treatment strategy for locally advanced lung cancer: a dosimetric study
}

\author{
${ }^{1} \mathrm{M}$. Ayadi, ${ }^{2}$ T. Baudier, ${ }^{3} \mathrm{G}$. Bouilhol, ${ }^{1} \mathrm{P}$. Dupuis, ${ }^{1} \mathrm{P}$. Boissard, ${ }^{2}$ R. Pinho, ${ }^{2}$ A. Krason, ${ }^{2} \mathrm{~S}$. Rit, \\ ${ }^{1}$ L. Claude and ${ }^{2} \mathrm{D}$. Sarrut \\ ${ }^{1}$ Radiotherapy and Physics Department, Leon Berard Cancer Center, 28, rue Laennec F-69373, Lyon, France \\ 2 Univ Lyon, INSA-Lyon, Université Lyon 1, CNRS, Inserm, Centre Léon Bérard, CREATIS UMR 5220, U1206, F- \\ 69373, Lyon, France \\ ${ }^{3}$ Department of Radiotherapy, Hartmann Radiotherapy Center, American Hospital of Paris, Neuilly, France \\ Br J Radiol 2020; 93: 20190692.
}

\begin{abstract}
Objectives

The internal target volume (ITV) strategy generates larger planning target volumes (PTVs) in locally advanced non-small cell lung cancer (LA-NSCLC) than the Mid-position (Midp) strategy. We investigated the benefit of the Mid-p strategy regarding PTV reduction and dose to the organs at risk (OARs).
\end{abstract}

\section{Methods}

44 patients with LA-NSCLC were included in a randomized clinical study to compare ITV and Mid-p strategies. GTV were delineated by a physician on MIP images and on Mid-p images from four-dimensional CTs. CTVs were obtained by adding $6 \mathrm{~mm}$ uniform margin for microscopic extension. CTV to PTV margins were calculated using the van Herk's recipe for setup and delineation errors. For the Mid-p strategy, the mean target motion amplitude was added as a random error. For both strategies, 3D conformal plans delivering 60 to $66 \mathrm{~Gy}$ to PTV were performed. PTVs, dose-volume parameters for OARs (lung, esophagus, heart, spinal cord) were reported and compared.

\section{Results}

With the Mid-p strategy, the median of volume reduction was $23.5 \mathrm{~cm}^{3}(p=0.012)$ and $8.8 \mathrm{~cm}^{3}(p=0.0083)$ for $\mathrm{PTV}_{\mathrm{T}}$ and $\mathrm{PTV}_{\mathrm{N}}$ respectively; the median mean lung dose (MLD) reduction was $0.51 \mathrm{~Gy}(p=0.0057)$. For $37.1 \%$ of the patients, delineation errors led to smaller PTV with the ITV strategy than with the Mid-p strategy.

\section{Conclusion}

PTV and MLD were significantly reduced using the Mid-p strategy. Delineation uncertainty can unfavorably impact the advantage.

\section{Advances in knowledge}

To the best of our knowledge, this is the first dosimetric comparison study between ITV and Mid-p strategies for LA-NSCLC.

Mid-p strategy significantly reduces tumor, nodal PTVs and MLD. 


\section{Introduction}

Treating locally advanced non-small cell lung cancer (LA-NSCLC) remains challenging with reported 5 -years survival rates around $10-20 \%$ [1]. Radiotherapy with prescribed doses of 60-66 Gy in 30-33 fractions, combined or not with chemotherapy, is the standard of care [2]. A critical problem in LA-NSCLC treatment is the tumor motion caused by patient breathing. Tumor motion leads to the use of large internal margins to define the Planning Target Volume (PTV) [3], potentially increasing normal lung toxicity.

Several breathing compensation methods, of variable complexity, are available and can be divided into two groups: active or passive techniques [4]. The most common passive technique is the Internal Target Volume (ITV) strategy [3]. Its simplicity has made it the preferred strategy but it is a "maximalist" approach because it is obtained by merging the Gross Tumor Volumes (GTV) of all breathing phases. The ITV is typically delineated on the Maximum Intensity Projection (MIP) CT image reconstructed from a four-dimensional (4D) CT image [5]. An innovative passive strategy introduced by Wolthaus et al. [6] is the Mid-position (Mid-p) strategy. Unlike the ITV strategy which uses fixed margins, the Mid-p strategy consists in planning the treatment on the time-averaged position of the breathing cycle described by the 4D CT image, with patient-specific margins depending on the amplitude of the tumor motion. This approach theoretically leads to a reduction of the PTV and, therefore, a reduction of the irradiated volume of normal tissues; up to $15 \%$ according to [7]. The same, Wanet et al. [8] recommended this technique for large tumors $(>1.5 \mathrm{~cm})$. Most of the studies in the literature focused on early-stage NSCLC treated by stereotactic body radiotherapy treatment for Mid-p [8] or Mid-ventilation (approximation of the Mid-p) [9] [10].

From October 2012 to May 2018, patients at our institution with LA-NSCLC were included in a phase 2 randomized study comparing the ITV strategy (control arm) with the Mid$p$ strategy. Here, the objective is to evaluate the dosimetric potential benefit of the Mid-p strategy with respect to the ITV strategy on a prospective trial for patients treated with conventional fractionated radiotherapy. In this paper, we only focus on dosimetric aspects: the PTV reduction with the Mid-p strategy and the benefits in terms of organ at risk (OAR) dose reduction (clinical aspects are not considered).

\section{Patients and methods}

\subsection{Image acquisition and processing}

44 patients with LA-NSCLC were included in a phase 2 randomized clinical trial to compare ITV and Mid-p strategies (16 were included in the ITV arm and 28 in the Mid-p arm). Those patients were setup either in an alpha cradle mold (Alpha Cradle Molds, Akron, USA) or in a BlueBAG ${ }^{T M}$ (Medical Intelligence, Schwabmuenchen, Germany), arms above the head. For each patient, a 4D CT image was acquired under normal free breathing with a Phillips Brillance Big Bore (Philips Medical System, Cleveland, USA) using a $2 \mathrm{~mm}$ slice width and the Pneumo Chest bellows belt. The pitch was adapted from 0.06 to 0.08 according to the patient breathing pattern. A ten-phases 4D CT image was reconstructed based on the respiratory signal phase. The blurred average, the MIP and the Mid-p images were automatically computed in house developed software. The MIP image was computed projecting the 4D image along the time axis and the Mid-p image was generated with Elastix, a deformable registration software [11]. The 50\% image (maximum exhale) was registered to the other nine phases using B-splines registration [12]. Sliding motion between the lungs and the rib-cage was accounted for with the motion mask strategy [13] when its automated segmentation was successful from a visual assessment, otherwise with an automated lung segmentation. If none of the two segmentations was successful, sliding motion correction was disabled. From the nine vector fields, the time average position (Mid-p) was computed and each phase image was warped towards the Mid-p. The median of these ten warped images was computed to finally 
generate the Mid-p image. A physicist and an expert in image processing visually validated all Mid-p images.

\subsection{Treatment plan}

Radiation oncologists delineated up to four tumor volumes for each patient on Monaco $^{\mathrm{TM}}$ version 5.11.02 (Elekta Oncology Systems, Crawley, West Sussex, UK): GTV (the primary tumor) and $G_{T V}$ (in case of nodal disease) on the Mid-p image, and internal GTV $\left(I G T V_{T}\right)$ and internal $G_{T V}\left(I G T V_{N}\right)$ on the MIP image. The primary tumor was delineated using a preset lung window and the lymph nodes were delineated using a preset soft tissue window. Heart, spinal cord, esophagus, brachial plexus, lungs were delineated as OARs on the average image used for the treatment plan. The clinical target volumes, CTV and ICTV, were obtained adding a $6 \mathrm{~mm}$ margin in all directions to the GTV and IGTV, respectively, to account for the sub-clinical disease [14]. The planning target volumes, PTV and IPTV, were obtained using van Herk's formula (assuming that the dose delivered to the CTV was at least $95 \%$ of the prescribed dose and for $90 \%$ of the population) including systematic $\Sigma$ and random $\sigma$ errors [15] [16]:

$$
\operatorname{Margin}=2.5 \sum+1.64 \sqrt{\sigma^{2}+\sigma_{p}^{2}}-1.64 \sigma_{p}
$$

with a penumbra width $\sigma_{p}=6.4 \mathrm{~mm}$ for lung treatment [10] [17]. For both Mid-P and ITV, the systematic errors $\Sigma$ and the random errors $\sigma$ considered positioning and delineation errors extracted from the literature [18] [19] (Table 1). Mid-P additionally included a random uncertainty for breathing motion equal to $36 \%$ of the peak-to-peak amplitude in all three directions [16]. Amplitudes were extracted in all volumes from deformation vector fields (DVF) obtained from the deformable registration.

\begin{tabular}{|c|c|c|c|c|c|c|}
\hline & \multicolumn{3}{|c|}{ Systematic $\Sigma$} & \multicolumn{3}{c|}{ Random $\sigma$} \\
\cline { 2 - 7 } & LR & CC & AP & LR & CC & AP \\
\hline Delineation [mm] & 4.0 & 4.0 & 4.0 & - & - & - \\
\hline Positioning [mm] & 1.3 & 1.7 & 1.4 & 2.7 & 3.5 & 2.4 \\
\hline Breathing [mm] & - & - & - & $0.36 \mathrm{~A}$ & $0.36 \mathrm{~A}$ & $0.36 \mathrm{~A}$ \\
\hline
\end{tabular}

Table 1: Systematic and random uncertainties in the 3 directions for margin calculation; A: amplitude, LR: left right, CC: cranio-caudal, AP: anterior posterior.

A three-dimensional conformal radiation therapy (3DCRT) treatment plan was planned for each strategy (ITV and Mid-p) on the average image using 8 to 10 static fields of 6 MV photon beams. Treatment plans for both arms were calculated using one of the two following B-type algorithm, the Superposition algorithm (XiO ${ }^{T M}$, CMS Inc., Saint Louis, US) or the Collapse Cone algorithm (Monaco ${ }^{\mathrm{TM}}$ ); a satisfying accordance was found in terms of dose calculation performance in inhomogeneous tissues between both algorithms [20]. The total prescribed dose to the PTV varied from 60 Gy to 66 Gy in 30 to 33 fractions depending on dose constraints reported by the French Radiotherapy Society [21]. Patients were all treated on a Synergy ${ }^{\mathrm{TM}}$ linear accelerator (Elekta Oncology Systems, Crawley, West Sussex, UK) with cone-beam CT image-guidance. The positioning uncertainty reported in Table 1 relies on conebeam CT acquired for the three first sessions and then once a week [19]. 


\subsection{Treatment plans analysis}

For all patients, tumor amplitude $\left(\mathrm{GTV}_{\mathrm{T}}, \mathrm{GTV} \mathrm{N}_{\mathrm{N}}\right)$ and calculated margins volumes were reported. Various dosimetric parameters defined by the clinical trial protocol were also reported: the dose received by $95 \%$ of the PTV $\left(D_{95}\right)$, the maximum dose $\left(D_{\max }\right)$ received by the spinal cord and the brachial plexus, the mean lung dose (MLD), the volume of lung (i.e. lungs minus PTVs) receiving at least $5 \mathrm{~Gy}, 20 \mathrm{~Gy}$, and $30 \mathrm{~Gy}\left(\mathrm{~V}_{5}, \mathrm{~V}_{20}, \mathrm{~V}_{30}\right)$, the volume of esophagus receiving at least 55 Gy $\left(V_{55}\right)$, the mean dose received by the heart $\left(D_{\text {mean }}\right)$, and the volume of heart receiving at least $40 \mathrm{~Gy}\left(\mathrm{~V}_{40}\right)$.

\section{Results}

\subsection{Patient characteristics}

The first 35 patients out of the 44 included patients were selected for this dosimetric analysis. Five patients were excluded due to poor 4D CT image quality, treatment modality change (modification for intensity modulated delivery due to extremely large tumor volume $>$ $1150 \mathrm{~cm}^{3}$ ), or cancelled treatment (intercurrent disease). Four other patients due to incomplete data. $74.3 \%$ of the patients were men. The mean age was 66.0 years with a standard deviation (SD) of 6.5 years. $48.6 \%$ of the patients had both parenchymal (or bronchial) and nodal diseases. The mean (range) GTV volume was $76.5 \mathrm{~cm}^{3}\left(1.7\right.$ to $\left.284.3 \mathrm{~cm}^{3}\right), \mathrm{GTV}_{\mathrm{N}}$ volume was $26.7 \mathrm{~cm}^{3}$ (1.4 to $\left.106.7 \mathrm{~cm}^{3}\right)$, IGTV volume was $87.7 \mathrm{~cm}^{3}\left(2.2\right.$ to $\left.298.9 \mathrm{~cm}^{3}\right)$, IGTV $\mathrm{N}_{\mathrm{N}}$ volume was $29.4 \mathrm{~cm}^{3}$ (1.6 to $110.8 \mathrm{~cm}^{3}$ ). The mean (range) PTV Tolume was $467.8 \mathrm{~cm}^{3}$ (83.8 to $\left.1109.7 \mathrm{~cm}^{3}\right)$, PTV $\mathrm{N}$ volume was $269.7 \mathrm{~cm}^{3}\left(98.3\right.$ to $\left.545.6 \mathrm{~cm}^{3}\right)$, IPTV volume was $492.1 \mathrm{~cm}^{3}$ (87.0 to $\left.1069.9 \mathrm{~cm}^{3}\right)$, IPTV volume was $383.3 \mathrm{~cm}^{3}\left(118.0\right.$ to $574.4 \mathrm{~cm}^{3}$ ).

\subsection{Tumor amplitude}

GTV $_{T}$ and $G T V_{N}$ amplitude statistics in all directions are shown in Figure 1. The median GTV $_{\mathrm{T}}$ amplitudes were $3.7 \mathrm{~mm}$ antero-posterior (AP), $3.0 \mathrm{~mm}$ left right (LR), $6.2 \mathrm{~mm}$ cranio-

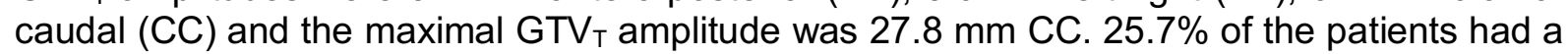
tumor amplitude larger than $10 \mathrm{~mm} \mathrm{CC}$. The median $\mathrm{GTV}_{\mathrm{N}}$ amplitudes were $3.3 \mathrm{~mm} \mathrm{AP,} 2.8$ $\mathrm{mm} \mathrm{LR}, 5.5 \mathrm{~mm} \mathrm{CC}$, and the maximal $\mathrm{GTV}_{\mathrm{N}}$ amplitude was $10.7 \mathrm{~mm} \mathrm{CC}$.

\subsection{Calculated margins for both strategies}

ICTV to IPTV calculated margins were fixed among patients: $11.3 \mathrm{~mm}$ AP, $11.4 \mathrm{~mm}$ LR and $12.3 \mathrm{~mm}$ CC. Calculated margins for Mid-p strategy are presented in Figure 2. The median of margins added to $\mathrm{CTV}_{\mathrm{T}}$ were $11.5 \mathrm{~mm} \mathrm{AP}, 11.5 \mathrm{~mm} \mathrm{LR}, 12.9 \mathrm{~mm} \mathrm{CC}$, with a maximal margin of $20.7 \mathrm{~mm}$ in CC. For $\mathrm{CTV}_{\mathrm{N}}$, the median of margins were $11.5 \mathrm{~mm} \mathrm{AP}, 11.5 \mathrm{~mm} \mathrm{LR}$, $12.8 \mathrm{~mm} \mathrm{CC}$, with a maximal margin of $13.9 \mathrm{~mm}$ in $\mathrm{CC}$. 


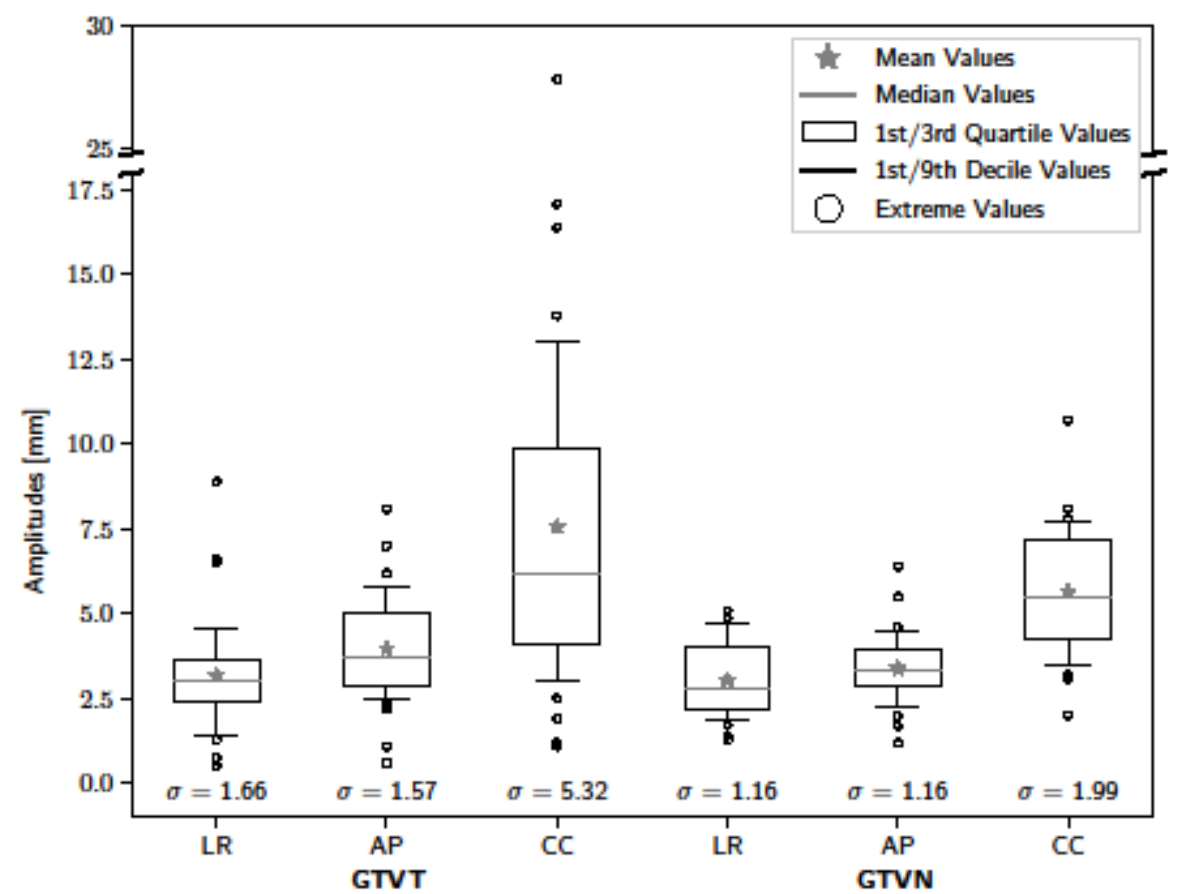

Figure 1: Mean, median, min-max amplitudes for GTVT and GTVN in the 3 directions.

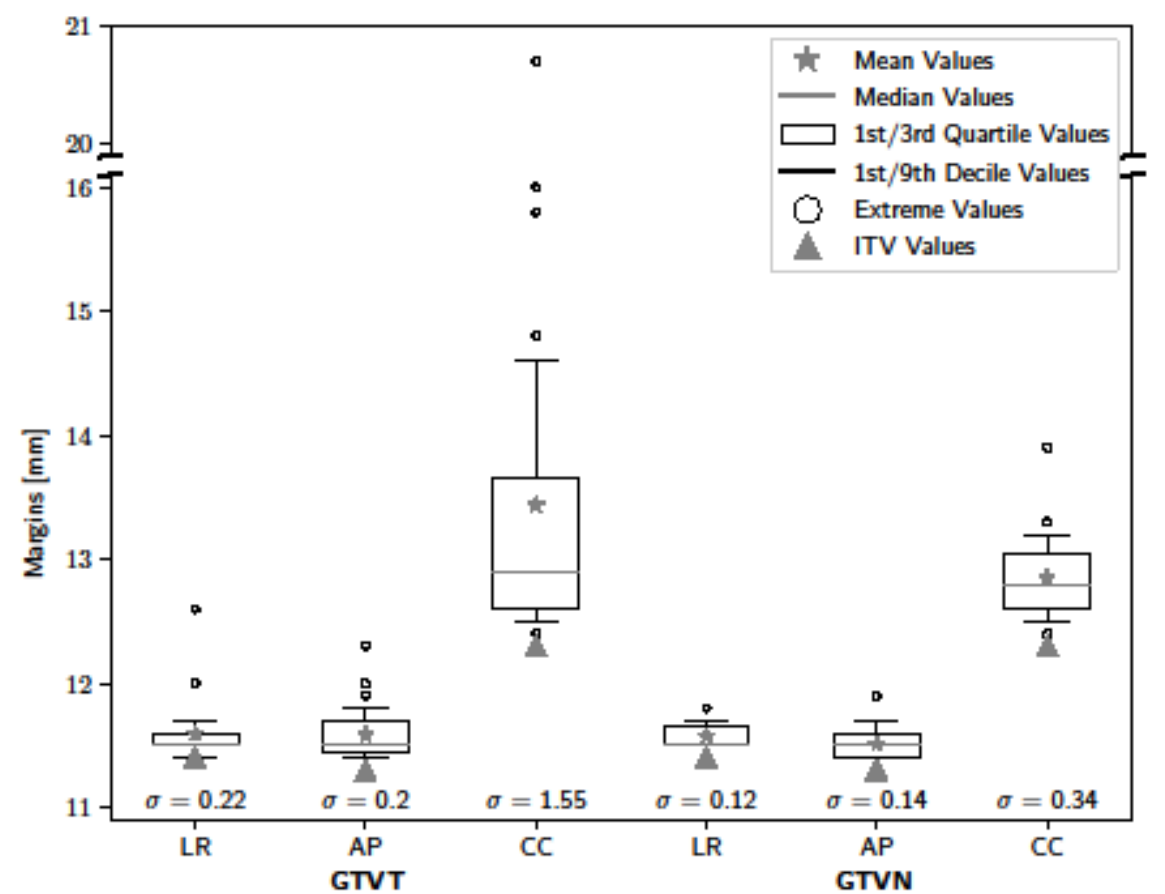

Figure 2: Calculated margins for tumor and nodes in the Mid-p strategy in the three directions.

\subsection{Volume reduction}

The Mid-p strategy led to smaller PTV $\mathrm{P}_{\mathrm{T}}$ and $\mathrm{PTV}_{\mathrm{N}}$ for $62.9 \%$ patients. The volume differences and corresponding statistics are presented for all patients in Figure 3. The median of volume reductions between IPTV $V_{T}$ and $P T V_{T}$ was $23.5 \mathrm{~cm}^{3}(p=0.012)$ and the one between IPTV $_{\mathrm{N}}$ and PTV $\mathrm{P}_{\mathrm{N}}$ was $8.8 \mathrm{~cm}^{3}(\mathrm{p}=0.0083)$. 


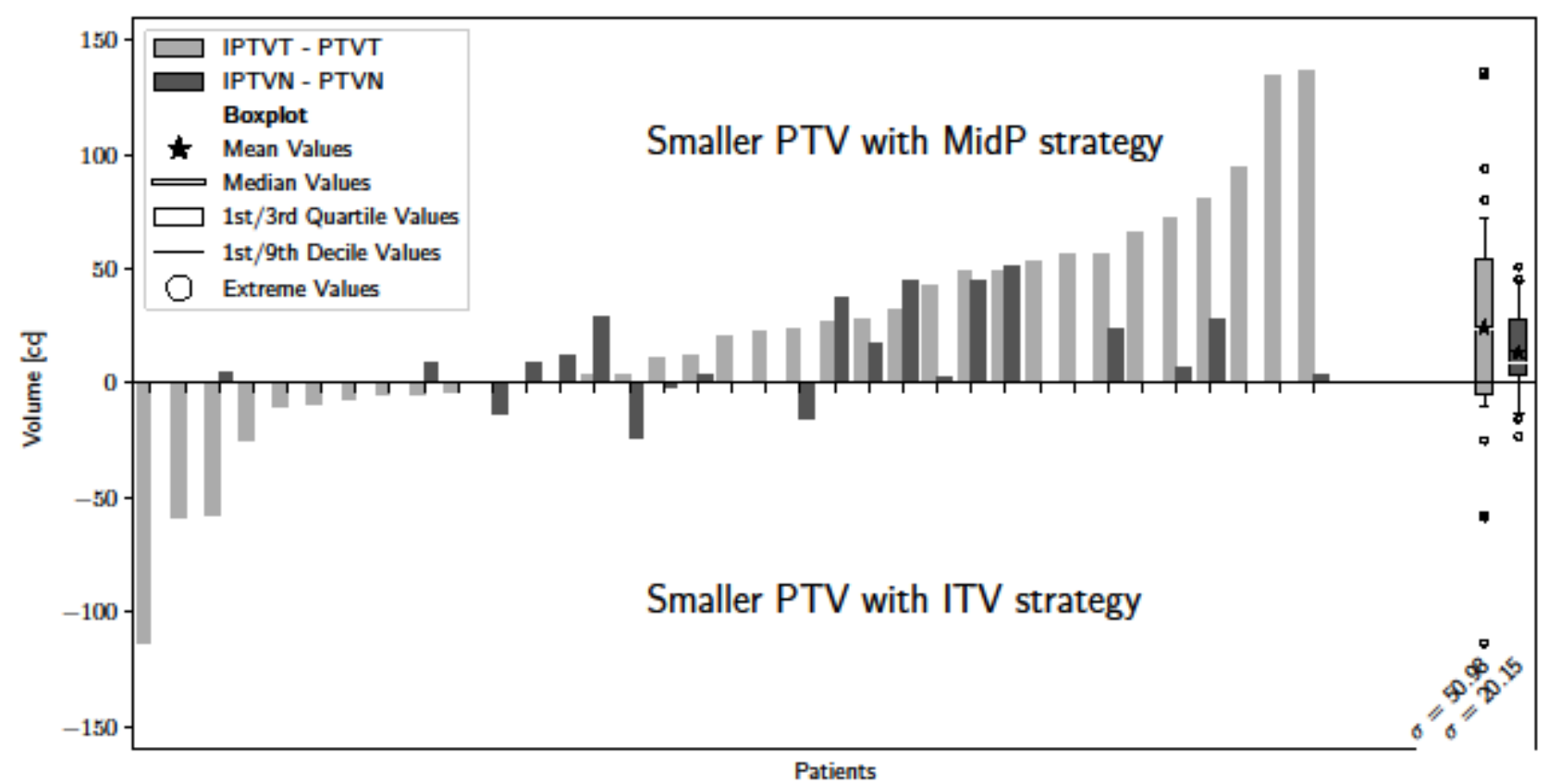

Figure 3: Volume differences for tumor and nodes for all patients and boxplots for all patients on the right. The patients are sorted from the smallest to the largest IPTVT - PTVT values.

\subsection{Dosimetric evaluation}

For the patient cohort, the mean prescribed dose was $63.9 \mathrm{~Gy}$ and the mean (range) PTV D 95 was $92 \%$ (82\% to $97 \%$ ). Between the ITV and the Mid-p plans, the differences in terms of dosimetric parameters for OARs have been listed in Table 2. A notable result in terms of mean difference (SD) was $0.51 \mathrm{~Gy}(1.0 \mathrm{~Gy}, \mathrm{p}=0.0057)$ for the MLD and positive for $71 \%$ of patients.

\begin{tabular}{|c|c|c|c|c|c|c|}
\hline \multicolumn{2}{|c|}{} & \multicolumn{5}{c|}{ Difference ITV - Mid-p for all patients } \\
\cline { 3 - 7 } \multicolumn{2}{|c}{} & mean & $\sigma$ & $\min$ & $\max$ & $\mathrm{p}$ \\
\hline \multirow{3}{*}{ Lung } & $\mathrm{D}_{\text {mean }}[\mathrm{Gy}]$ & 0.51 & 1.0 & -1.6 & 3.3 & $5.7 \times 10^{-3} *$ \\
\cline { 2 - 7 } & $\mathrm{V}_{5}\left[\mathrm{~cm}^{3}\right]$ & 43.0 & 122.1 & -172.0 & 396.0 & $4.8 \times 10^{-3} *$ \\
\cline { 2 - 7 } & $\mathrm{V}_{20}\left[\mathrm{~cm}^{3}\right]$ & 34.3 & 85.9 & -210.5 & 246.8 & $2.6 \times 10^{-3} *$ \\
\cline { 2 - 7 } & $\mathrm{V}_{30}\left[\mathrm{~cm}^{3}\right]$ & 24.6 & 57.3 & -73.6 & 230.3 & $1.7 \times 10^{-3} *$ \\
\hline \multirow{2}{*}{ Esophagus } & $\mathrm{V}_{55}\left[\mathrm{~cm}^{3}\right]$ & -0.53 & 5.8 & -33.45 & 4.4 & $5.9 \times 10^{-1}$ \\
\hline \multirow{3}{*}{ Heart } & $D_{\operatorname{mean}}[\mathrm{Gy}]$ & 0.65 & 2.7 & -5.2 & 9.8 & $1.7 \times 10^{-1}$ \\
\cline { 2 - 7 } & $\mathrm{V}_{40}[\%]$ & 0.37 & 3.1 & -8.1 & 5.3 & $5.0 \times 10^{-1}$ \\
\hline Spinal cord & $\mathrm{D}_{\max }[\mathrm{Gy}]$ & 0.33 & 1.3 & -1.8 & 4.7 & $1.3 \times 10^{-1}$ \\
\hline Brachial plexus & $\mathrm{D}_{\max }[\mathrm{Gy}]$ & -1.6 & 2.6 & -6.4 & 0.7 & $2.7 \times 10^{-1}$ \\
\hline
\end{tabular}

Table 2: Difference between ITV plan and Mid-p plan in terms of dose received by OARs.

${ }^{*}$ means significant results with $p<0.01$. 


\section{Discussion}

\subsection{GTV volumes}

The GTV and IGTV sizes for the patient cohort shown in 3.1 were similar to [7] [8], mean $G_{T V}$ and $G T V_{N}$ volumes were smaller on average than mean IGTV $V_{T}$ and $I G T V_{N}$ volumes. This difference between $G_{T V}$ and IGTV $V_{T}$ volumes is consistent with previous studies [22]. GTV volume should be close to the tumor volume obtained from a single breathing phase while the IGTV volume encompassed all the tumor positions during the patient breathing. We noticed that for 4 patients, the GTV $\mathrm{T}_{\mathrm{T}}$ is larger than the IGTV patients with a GTV larger for the Mid-p strategy than for the ITV strategy, this can be explained by contouring uncertainties. Indeed, visual analysis showed that tumors were in the bronchial area (or located close to the mediastinum) with poor contrast leading to difficulties for delineation [22]. For the other patients, the difference was due to inconsistent contours, mainly at the tumor boundaries. Similarly, for the nodal volumes, low contrast in mediastinum increased the delineation uncertainty, independently of Mid-p or MIP image [22]. In these particular cases, a positron emission tomography (PET) and/or magnetic resonance imaging (MRI) would have probably helped in reducing delineation uncertainty [23] [24] [25] [26].

\subsection{Tumor amplitude}

Like observed in previous studies [27] [28], the largest component of the lung tumor and nodes motions was in the $\mathrm{CC}$ direction. The median peak-to-peak amplitudes were similar for both $\left(G_{T V}\right.$ and $\left.G_{T V}\right)$ with $6.5 \mathrm{~mm}$ and $6.0 \mathrm{~mm}$, respectively. These results are comparable to those reported by Schaake et al. [29]. The maximum peak-to-peak amplitude for the GTV ${ }_{T}$ was much larger than that of the GTV $_{N}(27.8 \mathrm{~mm}$ vs $10.7 \mathrm{~mm})$ because this $\mathrm{GTV}_{T}$ was located in the left inferior lobe, a common behavior for tumors close to the diaphragm.

\subsection{PTV and margins}

The mean PTVT and PTVN volume reductions were $6.5 \%$ and $6.8 \%$ respectively. Wolthaus et al. found $15 \%$ of reduction for various stages of lung cancer [7]. On one hand, the differences could be explained by a large SD $\left(10.5 \%\right.$ for PTV $\mathrm{V}_{\mathrm{T}}$ and $8.7 \%$ for IPTV $\left.\mathrm{V}_{\mathrm{T}}\right)$ in this study. On the other hand, their methodology was different: no CTV margins were used, an ITV motion expansion was used to determine the IPTV $\mathrm{V}_{\mathrm{T}}\left(\mathrm{GTV}_{\mathrm{T}}\right.$ plus half of the peak-to-peak tumor amplitude), the periodic motion uncertainty was one third of the amplitude and the patient repositioning systematic and random uncertainty values were different due to a different protocol. In our study, the IGV Tas delineated with the MIP image exclusively. The difference of PTV volume reduction between our study and Wolthaus et al. could be partly explained by the difference between ITV margins and Mid-p margins. Considering the example given in [7] of a peak-to-peak tumor motion of $15 \mathrm{~mm}$ in $\mathrm{CC}$ direction and an off-line setup correction, we obtain with our uncertainty values, a margin of $19.8 \mathrm{~mm}$ for ITV strategy and $15.3 \mathrm{~mm}$ for Midp strategy (versus $20.2 \mathrm{~mm}$ and $14.9 \mathrm{~mm}$ respectively in [7]).

For $62.9 \%$ of the patients, the PTV volume was significantly smaller than the IPTV This difference was less important than with the GTV $(88.6 \%)$. For the patients with larger PTV in the Mid-p strategy compared to the IPTV in the ITV strategy (patients with negative values 


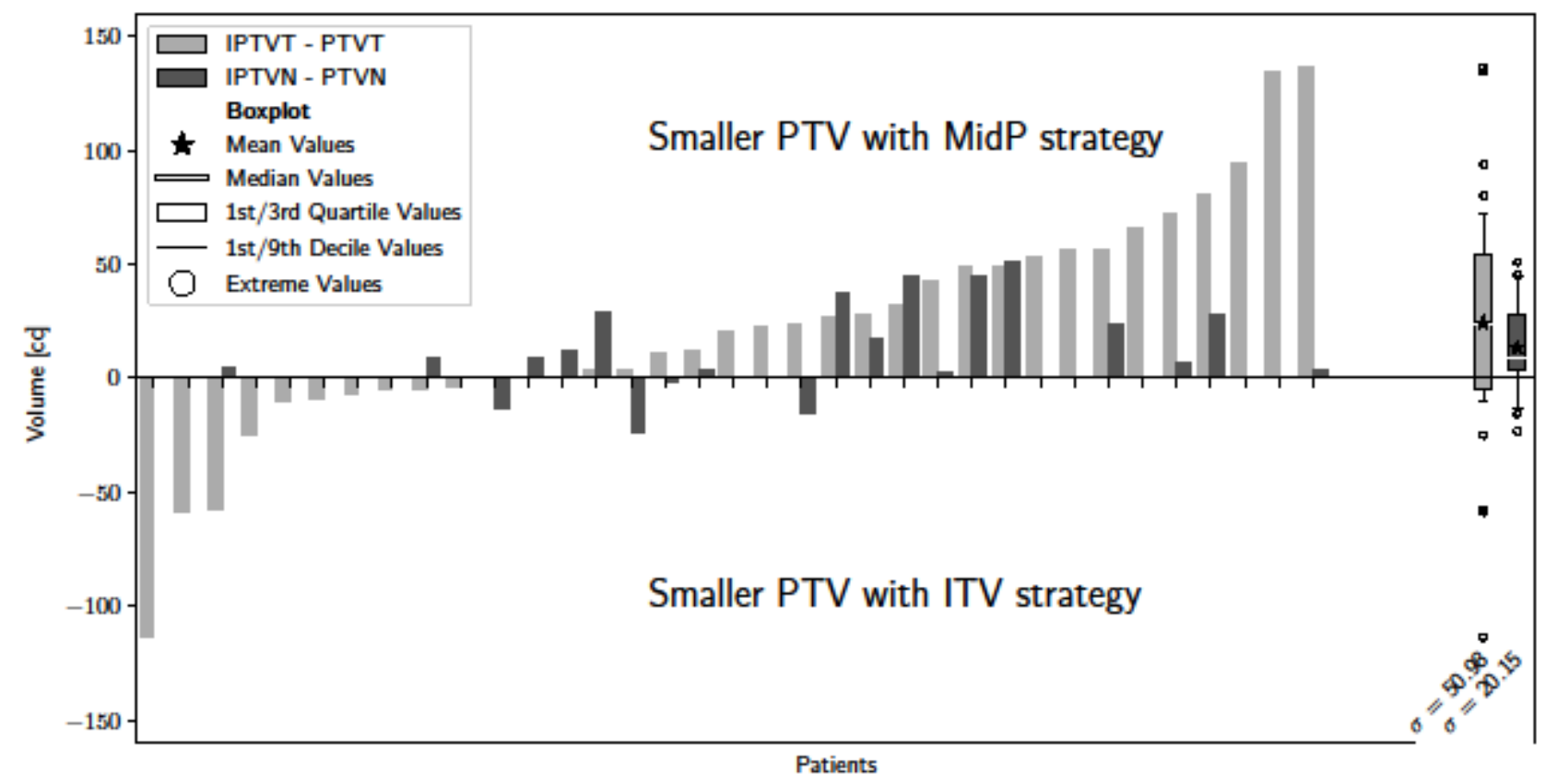

Figure 3), the delineation errors were predominant.

\subsection{Dosimetric analysis}

For 9 patients, margins have been reduced to respect the OAR dose constraints and in most cases, the tumor motion amplitude was larger than $10 \mathrm{~mm}$ in the CC direction. To our knowledge, no clinical study has been dedicated to the dosimetric comparison of different motion management strategies. With the Mid-p strategy, the mean MLD reduction was 0.51 Gy. The results corroborate Ehrbar's results [30]; a strategy change involving a PTV reduction leads to a MLD diminution. As MLD is correlated to lung toxicity, a clinical benefit could be expected in the medium term [31]. Among all patients, the minimum PTV $D_{95}$ was $82 \%$. This unsatisfying coverage was in that case due to the plexus brachial proximity. Moreover, during the study, a dose calculation algorithm change in our department mainly led to a decrease of the PTV coverage; but it did not affect the intra patient results. Concerning the mean heart dose, it was reduced by 0.65 Gy with the Mid-p strategy. Given that the overall survival for LANSCLC is poor and that patients frequently have co-morbidities that increase heart disease risks, cardiac late toxicities related to radiotherapy are difficult to describe. Recently, Speirs et al. [32] showed that the heart dose was correlated with the overall survival (especially V50 > $25 \%$ ) and the cardiac toxicity. In our patient cohort, the mean heart V40 was less than $12.2 \%$ for both strategies and the larger heart V40 difference for one patient between MIP and Mid-p strategy was $5.3 \%$ ( $5.4 \%$ vs $0.1 \%$ respectively). In this latter case, this difference could be explained by non-reproducibility in delineation: the IGTV $\mathrm{T}_{\mathrm{T}}$ inferior edge was delineated closer to the heart compared to the $\mathrm{GTV}_{\mathrm{T}}$ one.

From a general point of view, inverse planning and intensity modulated radiation therapy would have further increased the benefit of Mid-p strategy by improving PTV coverage while minimizing the dose received by OARs [33] [34] [35]. These treatments planning strategies would have been applicable to the presented cohort because the interplay effect is negligible [36].

\subsection{Limitations}

The 4D CT image is based on one average respiratory cycle so it is sensitive to irregularities of the patient breathing. Breathing motion artifacts can lead to GTV size errors. For this study, the breathing pattern of each patient was systematically checked on the 4D CT reconstruction before clinical use. In case of large amplitude variations in the respiratory trace 
and artifacts at the level of the tumor, a second 4D CT image was acquired. Only one patient was excluded from the study due to poor image quality.

To be in agreement with our current clinical practice, the Mid-p and MIP target volumes were delineated independently by a single radiation oncologist leading to a delineation variability in our study. Patients with better ITV strategy than Mid-p strategy had larger GTV than IGTV $V_{T}$ due to clear inconsistent delineations. Consequently, for the latter cases, PTV were larger than IPTV $\mathrm{T}$ in Figure 3. Methodologies to reduce this uncertainty should be considered, e.g., a double-check delineation for quality assurance, a contour propagation from Mid-p to ITV, a better definition of the nodes or nodes area that need to be irradiated.

The same penumbra $\sigma_{p}=0.64 \mathrm{~cm}$ in equation Margin=2.5 $\sum+1.64 \sqrt{\sigma^{2}+\sigma_{p}^{2}}-$ $1.64 \sigma_{p} \quad$ (1) was used for both tumor and nodes in the margin recipe to simplify the margin calculation process. For nodes in the mediastinum, a $\sigma_{p}$ of $0.32 \mathrm{~cm}$ may have been used because the penumbra in soft tissues is narrower [17]. In the same way, $\Sigma$ in equation Margin=2.5 $\sum+1.64 \sqrt{\sigma^{2}+\sigma_{p}^{2}}-1.64 \sigma_{p} \quad$ (1) could be reduced using a daily cone beam CT (CBCT) by nullify the systematic setup error for the tumor [37]. However, Rit et al. [38] shown that the variability of breathing amplitude have a limited impact on the margins.

\section{Conclusion}

This dosimetric study aimed at comparing PTVs and doses received by OARs for two passive breathing compensation methods, the ITV strategy and the Mid-p strategy, for patients with LA-NSCLC treated with 3DCRT. The Mid-p strategy leads to significant target volume and MLD reduction even if delineation uncertainties unfavorably impacted the Mid-p advantage for one third of the patients. The benefit of the Mid-p strategy over the ITV strategy has to be confirmed with the clinical analysis of local tumor control and toxicity reduction.

\section{Acknowledgment}

This work was partly supported by the SIRIC LYriCAN: INCa-DGOS-Inserm_12563.

\section{Reference}

[1] C. Allemani, H. K. Weir, H. Carreira, R. Harewood, D. Spika, X. S. Wang, F. Bannon, J. V. Ahn, C. J. Johnson, A. Bonaventure, R. Marcos-Gragera, C. Stiller, G. Azevedo E Silva, W. Q. Chen, O. J. Ogunbiyi, B. Rachet, M. J. Soeberg, H. You, T. Matsuda, M. Bielska-Lasota, H. Storm, T. C. Tucker et M. P. Coleman, «Global surveillance of cancer survival 1995-2009: Analysis of individual data for 25676887 patients from 279 population-based registries in 67 countries (CONCORD-2), » The Lancet, vol. 385, pp. 977-1010, 2015.

[2] P. E. Postmus, K. M. Kerr, M. Oudkerk, S. Senan, D. A. Waller, J. Vansteenkiste, C. Escriu et S. Peters, «Early and locally advanced non-small-cell lung cancer (NSCLC): ESMO Clinical Practice Guidelines for diagnosis, treatment and follow-up, » Annals of Oncology, vol. 28, July, p. 1, 2017.

[3] ICRU, ICRU Report 62: Prescribing, Recording and Reporting Photon Beam Therapy, 1999.

[4] P. J. Keall, G. S. Mageras, J. M. Balter, R. S. Emery, K. M. Forster, S. B. Jiang, J. M. Kapatoes, D. A. Low, M. J. Murphy, B. R. Murray, C. R. Ramsey, M. Van Herk, S. S. Vedam, J. W. Wong et E. 
Yorke, «The management of respiratory motion in radiation oncology report of AAPM Task Group 76.,» Medical physics, vol. 33, pp. 3874-3900, 2006.

[5] R. Underberg, F. J. Lagerwaard, B. J. Slotman, J. P. Cuijpers et S. Senan, «Use of maximum intensity projections (MIP) for target volume generation in 4DCT scans for lung cancer," International Journal of Radiation Oncology Biology Physics, vol. 63, pp. 253-260, 2005.

[6] J. Wolthaus, J.-J. Sonke, M. Van Herk et E. Damen, «Reconstruction of a time-averaged midposition CT scan for radiotherapy planning of lung cancer patients using deformable registration.," Medical physics, vol. 35, pp. 3998-4011, 2008.

[7] J. Wolthaus, J.-J. Sonke, M. Van Herk, J. Belderbos, M. Rossi, J. V. Lebesque et E. Damen, «Comparison of different strategies to use four-dimensional computed tomography in treatment planning for lung cancer patients., I International Journal of Radiation Oncology Biology Physics, vol. 70, pp. 1229-1238, 2008.

[8] M. Wanet, E. Sterpin, G. Janssens, A. Delor, J. A. Lee et X. Geets, «Validation of the mid-position strategy for lung tumors in helical TomoTherapy," Radiotherapy and Oncology, vol. 110, pp. 529-537, 2014.

[9] H. Peulen, J. Belderbos, M. Rossi et J.-J. Sonke, «Mid-ventilation based PTV margins in Stereotactic Body Radiotherapy (SBRT): A clinical evaluation,» Radiotherapy and Oncology, vol. 110, pp. 511-516, 2014.

[10] J.-J. Sonke, M. Rossi, J. Wolthaus, M. van Herk, E. Damen et J. Belderbos, «Frameless Stereotactic Body Radiotherapy for Lung Cancer Using Four-Dimensional Cone Beam CT Guidance,» International Journal of Radiation Oncology Biology Physics, vol. 74, pp. 567-574, 2009.

[11] S. Klein, M. Staring, K. Murphy, M. A. Viergever et J. Pluim, «elastix: A Toolbox for IntensityBased Medical Image Registration," IEEE Transactions on Medical Imaging, vol. 29, pp. 196-205, 2010.

[12] D. Rueckert, L. I. Sonoda, C. Hayes, D. L. Hill, M. O. Leach et D. J. Hawkes, «Nonrigid registration using free-form deformations: application to breast MR images.," IEEE Transactions on Medical Imaging, vol. 18, pp. 712-721, 1999.

[13] J. Vandemeulebroucke, O. Bernard, S. Rit, J. Kybic, P. Clarysse et D. Sarrut, «Automated segmentation of a motion mask to preserve sliding motion in deformable registration of thoracic CT,» Medical Physics, vol. 39, pp. 1006-1015, 2012.

[14] P. Giraud, M. Antoine, A. Larrouy, B. Milleron, P. Callard, Y. De Rycke, M. F. Carette, J. C. Rosenwald, J. M. Cosset, M. Housset et E. Touboul, «Evaluation of microscopic tumor extension in non-small-cell lung cancer for three-dimensional conformal radiotherapy planning," International Journal of Radiation Oncology Biology Physics, vol. 48, pp. 1015-1024, 2000. 
[15] M. Van Herk, P. Remeijer, C. Rasch et J. V. Lebesque, «The probability of correct target dosage: Dose-population histograms for deriving treatment margins in radiotherapy," International Journal of Radiation Oncology Biology Physics, vol. 47, pp. 1121-1135, 2000.

[16] M. Van Herk, M. G. Witte, J. Van Der Geer, C. Schneider et J. V. Lebesque, «Biologic and physical fractionation effects of random geometric errors,» International Journal of Radiation Oncology Biology Physics, vol. 57, pp. 1460-1471, 2003.

[17] M. G. Witte, J. Van Der Geer, C. Schneider, J. V. Lebesque et M. Van Herk, «The effects of target size and tissue density on the minimum margin required for random errors, 》 Medical Physics, vol. 31, pp. 3068-3079, 2004.

[18] R. Steenbakkers, J. C. Duppen, I. Fitton, K. Deurloo, L. J. Zijp, A. Uitterhoeve, P. Rodrigus, G. Kramer, J. Bussink, K. De Jaeger, J. Belderbos, A. Hart, P. Nowak, M. Van Herk et C. Rasch, "Observer variation in target volume delineation of lung cancer related to radiation oncologistcomputer interaction: A 'Big Brother' evaluation,» Radiotherapy and Oncology, vol. 77, pp. 182190, 2005.

[19] J. Higgins, A. Bezjak, A. Hope, T. Panzarella, W. Li, J. Cho, T. Craig, A. Brade, A. Sun et J. P. Bissonnette, "Effect of image-guidance frequency on geometric accuracy and setup margins in radiotherapy for locally advanced lung cancer, » International Journal of Radiation Oncology Biology Physics, vol. 80, pp. 1330-1337, 2011.

[20] W.-Z. Chen, Y. Xiao et J. Li, «Impact of dose calculation algorithm on radiation therapy,» World Journal of Radiology, vol. 6, p. 874, 2014.

[21] SFRO, Guide Des Procedures De Radiotherapie Externe, 2007.

[22] S. Mercieca, J. Belderbos, K. De Jaeger, D. Schinagl, N. Van Der Voort Van Zijp, J. Pomp, J. Theuws, J. Khalifa, P. Van De Vaart et M. Van Herk, «Interobserver variability in the delineation of the primary lung cancer and lymph nodes on different four-dimensional computed tomography reconstructions," Radiotherapy and Oncology, 2017.

[23] V. Ambrosini, S. Nicolini, P. Caroli, C. Nanni, A. Massaro, M. C. Marzola, D. Rubello et S. Fanti, «PET/CT imaging in different types of lung cancer: An overview,» European Journal of Radiology, vol. 81, pp. 988-1001, 2012.

[24] A. Van Baardwijk, G. Bosmans, L. Boersma, J. Buijsen, S. Wanders, M. Hochstenbag, R. J. Van Suylen, A. Dekker, C. Dehing-Oberije, R. Houben, S. M. Bentzen, M. Van Kroonenburgh, P. Lambin et D. De Ruysscher, «PET-CT-Based Auto-Contouring in Non-Small-Cell Lung Cancer Correlates With Pathology and Reduces Interobserver Variability in the Delineation of the Primary Tumor and Involved Nodal Volumes, » International Journal of Radiation Oncology Biology Physics, vol. 68, pp. 771-778, 2007. 
[25] H. Bainbridge, A. Salem, R. Tijssen, M. Dubec, A. Wetscherek, C. V. Van Es, J. Belderbos, C. Faivre-Finn et $F$. McDonald, «Magnetic resonance imaging in precision radiation therapy for lung cancer,» Translational Lung Cancer Research, vol. 6, pp. 689-707, 2017.

[26] D. Groheux, G. Quere, E. Blanc, C. Lemarignier, L. Vercellino, C. De Margerie-Mellon, P. Merlet et S. Querellou, «FDG PET-CT for solitary pulmonary nodule and lung cancer: Literature review," Diagnostic and Interventional Imaging, vol. 97, pp. 1003-1017, 2016.

[27] Y. Seppenwoolde, H. Shirato, K. Kitamura, S. Shimizu, M. Van Herk, J. V. Lebesque et K. Miyasaka, «Precise and real-time measurement of 3D tumor motion in lung due to breathing and heartbeat, measured during radiotherapy, International Journal of Radiation Oncology Biology Physics, vol. 53, pp. 822-834, 2002.

[28] E. D. Donnelly, P. J. Parikh, W. Lu, T. Zhao, K. Leichleiter, M. Nystrom, J. P. Hubenschmidt, D. A. Low et J. D. Bradley, «Assessment of Intra-Fraction Mediastinal and Hilar Lymph Node Movement and Comparison to Lung Tumor Motion Using Four- Dimensional CT,» International Journal of Radiation Oncology Biology Physics, vol. 69, pp. 580-588, 2007.

[29] E. E. Schaake, M. Rossi, W. A. Buikhuisen, J. A. Burgers, A. Smit, J. Belderbos et J.-J. Sonke, «Differential motion between mediastinal lymph nodes and primary tumor in radically irradiated lung cancer patients, » International Journal of Radiation Oncology Biology Physics, vol. 90, pp. 959-966, 2014.

[30] S. Ehrbar, A. Jöhl, A. Tartas, L. S. Stark, O. Riesterer, S. Klöck, M. Guckenberger et S. TanadiniLang, «ITV, mid-ventilation, gating or couch tracking: A comparison of respiratory motionmanagement techniques based on 4D dose calculations, " Radiotherapy and Oncology, vol. 124, pp. 80-88, 2017.

[31] J. D. Bradley, A. Hope, I. El Naqa, A. Apte, P. E. Lindsay, W. Bosch, J. Matthews, W. Sause, M. V. Graham et J. O. Deasy, «A Nomogram to Predict Radiation Pneumonitis, Derived from a Combined Analysis of RTOG 9311 and Institutional Data,» International Journal of Radiation Oncology Biology Physics, vol. 69, pp. 985-992, 2007.

[32] C. K. Speirs, T. A. DeWees, S. Rehman, A. Molotievschi, M. A. Velez, D. Mullen, S. Fergus, M. Trovo, J. D. Bradley et C. G. Robinson, «Heart Dose Is an Independent Dosimetric Predictor of Overall Survival in Locally Advanced Non Small Cell Lung Cancer, "Journal of Thoracic Oncology, vol. 12, pp. 293-301, 2017.

[33] J. A. Christian, J. L. Bedford, S. Webb et M. Brada, «Comparison of inverse-planned threedimensional conformal radiotherapy and intensity-modulated radiotherapy for non-small-cell lung cancer, „International Journal of Radiation Oncology Biology Physics, vol. 67, pp. 735-741, 2007.

[34] S. G. Chun, C. Hu, H. Choy, R. U. Komaki, R. D. Timmerman, S. E. Schild, J. A. Bogart, M. C. Dobelbower, W. Bosch, J. M. Galvin, V. S. Kavadi, S. Narayan, P. Iyengar, C. G. Robinson, R. B. Wynn, A. Raben, M. E. Augspurger, R. M. MacRae, R. Paulus et J. D. Bradley, «Impact of 
intensity-modulated radiation therapy technique for locally advanced non-small-cell lung cancer: A secondary analysis of the NRG oncology RTOG 0617 randomized clinical trial, „ Journal of Clinical Oncology, vol. 35, pp. 56-62, 2017.

[35] D. Rousseau, D. Autret, S. Krhili, S. Yossi, A. Dupas, M. Édouard, M. A. Mahé, P. Giraud, C. Le Péchoux, P. Cellier, F. Denis et A. Paumier, «Are there any dosimetric advantages in using VMAT for treatment of locally advanced non-small cell lung cancer?,» Cancer/Radiotherapie, vol. 16, pp. 619-626, 2012.

[36] T. Bortfeld, S. B. Jiang et E. Rietzel, «Effects of Motion on the Total Dose Distribution," Seminars in Radiation Oncology, vol. 14, pp. 41-51, 2004.

[37] D. S. Møller, M. I. Holt, M. Alber, M. Tvilum, A. A. Khalil, M. M. Knap et L. Hoffmann, «Adaptive radiotherapy for advanced lung cancer ensures target coverage and decreases lung dose,» Radiotherapy and Oncology, vol. 121, pp. 32-38, 2016.

[38] S. Rit, M. Van Herk, L. J. Zijp et J.-J. Sonke, «Quantification of the variability of diaphragm motion and implications for treatment margin construction," International Journal of Radiation Oncology Biology Physics, vol. 82, p. 399, 2012. 